\title{
Microfinance Complementarity and Trade-Off between Financial Performance and Social Impact
}

\author{
Trong V. Ngo ${ }^{1}$ \\ ${ }^{1}$ Banking University HCMC, Vietnam \\ Correspondence: Trong V. Ngo, Banking University, 39 Ham Nghi Street, District 1, Ho Chi Minh City, Vietnam. \\ E-mail: trongnv@buh.edu.vn
}

Received: August 19, 2015

Accepted: September 22, 2015

Online Published: October 25, 2015

doi:10.5539/ijef.v7n11p128

URL: http://dx.doi.org/10.5539/ijef.v7n11p128

\begin{abstract}
There is a widespread belief that providing access to financial services (microfinance) or reaching the poor with microcredit are perfect solutions to establish a sustainable economy or to help kick-start a bottom-up recovery and social development animated by the poor themselves through self-employment and microenterprises. Microfinance has therefore become an important instrument for poverty alleviation and for improving the welfare of the poor in both developing and transition economies. Due to the difficulty of targeting the poor, who have a lack of collateral, microfinance institutions (MFIs) are called on to achieve a balance between social impact (poverty reduction) and positive financial performance. This paper assumes that the financial objectives of MFIs operate in opposition to each other and that a trade-off is inevitable. Unbalanced panel data of MFIs for the period 1995-2013 has been extracted from the MIX Market website. In order to solve the endogeneity problem, this paper employed the dynamic system GMM (generalized method of moments) of Blundell and Bond (1998) that is considered as the new methodology currently in use in the empirical investigation of the financial performance in banking and finance. This paper outlines some of the parameters that affect the nature of trade-offs and complementarities between social and financial objectives in microfinance performance, and provides empirical evidence from cross-country analysis. Sustainability has a positive link with outreach. MFIs tend to expand their outreach in order to achieve sustainability, based on the advantages of the economies of scale. However, a threshold which makes the trade-offs or complementarities between financial and social objectives reverse if it goes beyond a certain point is also observed.
\end{abstract}

Keywords: poverty reduction, financial performance, social impact, microfinance institutions (MFIs), sustainability

\section{Microfinance Performance}

Microfinance gives the poor opportunities to overcome poverty and become self-sufficient by running small businesses. Commercial microfinance typically does not reach the poorest people (outreach), who are intentionally reached by the government and donors through non-profit programs. Whether the focus is primarily on the poorest or not, microfinance tends to depend heavily on the community, where people live together, interact with others, and build their relationships like fishing nets (Worakul, 2006). Therefore, the combination in microfinance between profit and non-profit programs should ideally be for the development of the community, instead of focusing on a specific group of the poor, such as the poorest or the moderately poor (Note 1). The performance of MFIs is typically measured in four main critical areas: outreach, sustainability (Note 2), efficiency, and portfolio quality (Rosenberg, 2009). These core indicators are categorized into two groups: financial and social performance. Sustainability, efficiency and portfolio quality are indicators of financial performance. On the other hand, outreach captures the social performance of MFIs. These indicators do not capture all the relevant aspects of the performance of MFIs for internal management, but they ideally represent the minimum performance areas for the basic investigations of external investors. At the core are questions about the trade-offs and choices in the combination of financial and social objectives (see Figure 1 below).

Social performance refers to the developmental objective of MFIs, or the impact of providing access to financial services (microfinance) for the poor (Hossain \& Knight, 2008; Rosenberg, 2009; Littlefield \& Kneiding, 2009). The two most usual aspects of outreach are its depth and breadth. Depth of outreach refers to the poverty level of the clients served, while breadth of outreach refers to the scale of operations of an MFI. The most common 
indicators recommended to measure outreach are average loan balance per borrower (ALB) and number of active borrowers (NAB). Expanding outreach is an ultimate goal of almost all MFIs, but rapid expansion sometimes proves to be unsustainable, especially during an MFI's early years. In addition, it is often feared that there are insufficient public funds for the subsidized microfinance programs, and MFIs cannot remain viable.

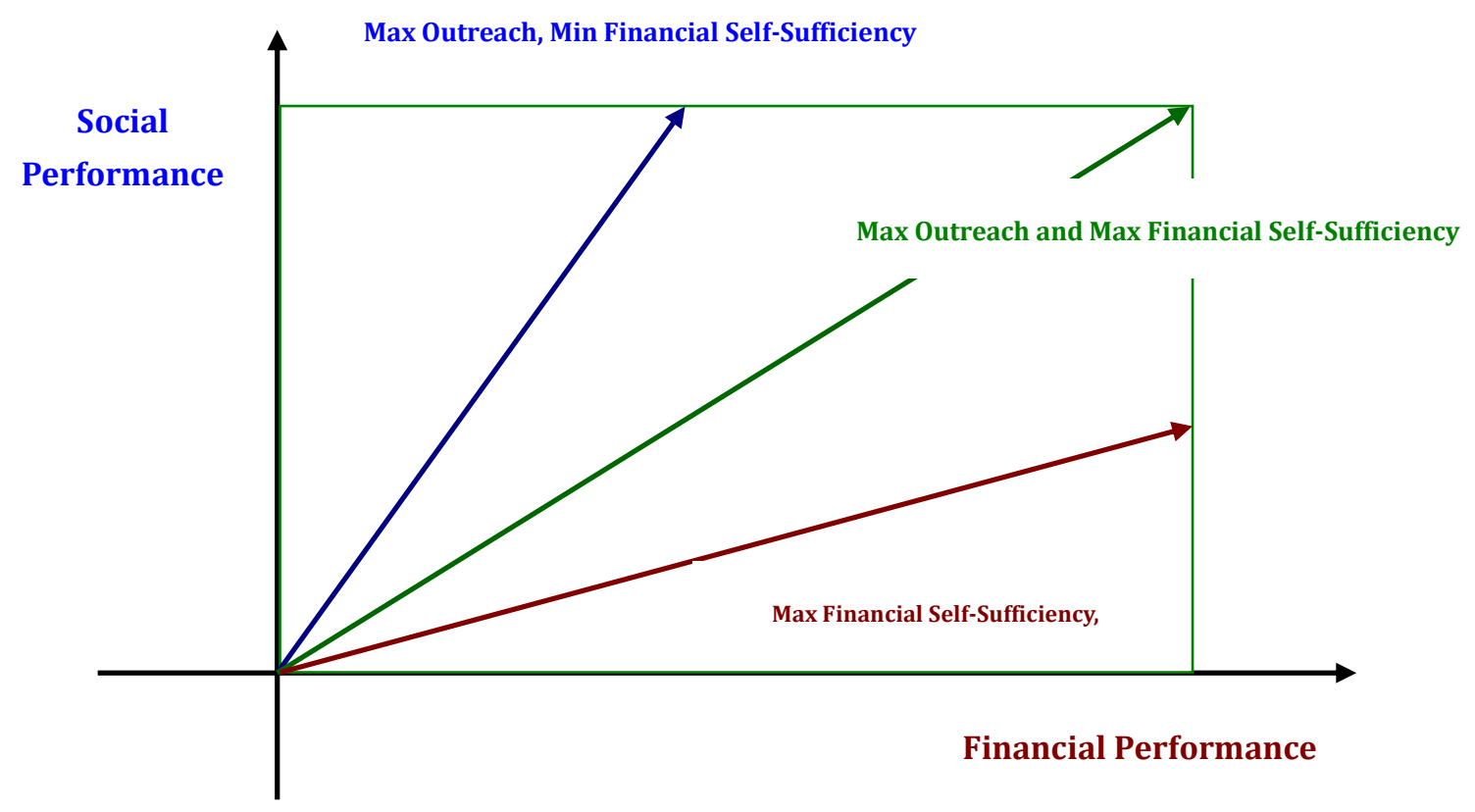

Figure 1. Trade-off between financial and social performance

Sources: Robinson (2001); Zeller and Myer (2003); Charitonenko and Rahman (2002); Copestake et al. (2005); Gonzalez (2010).

Financial performance refers to the ability to cover all administrative costs, loan losses, and financing costs from operating income (Rosenberg, 2009). Among indicators proposed for financial performance, sustainability emphasizes the importance of economic viability and refers to the ability of a microfinance program or an MFI to continuously carry out activities and services in pursuit of its statutory objectives. The sustainability concept provides a framework for increasing performance towards social objectives in even yield-orientated MFIs. This is in contrast to the earlier win-win vision of MFIs, which rapidly reached their targeted scale and outreach, bringing about positive impacts on large numbers of the world's poor people, whilst at the same time becoming operationally self-sufficient and therefore no longer dependent on external funding. MFIs can maintain and expand their financial services in the long run, unless they are unable to cover all of their costs and generate net income. Therefore, sustainability basically refers to profitability or commercial microfinance. Debates about the potential for microfinance to achieve social as well as financial goals are, however, hindered by a lack of information, in particular on social performance. Lack of social performance data reinforces the tendency to focus on what is measurable and available in financial statements. Most MFIs, therefore, respond more to financial pressures and signals than social signals in their management information systems and become more focused on achieving their financial, rather than their social, objectives. According to this approach, since MFIs are viewing their activities more and more as profitable businesses, it is important to constantly look for possible cost reductions to operate profitably and to be economically viable (Hermes et al., 2011). It has been pointed out repeatedly that MFIs need to be economically viable and sustainable in the long run, since their sustainability is not possible without sound financial performance. In spite of the fact that MFIs can improve their financial performance to achieve a targeted outreach, there are some sceptics who argue that there is a trade-off between sustainability and social mission.The most common measure of profitability is return on assets (ROA), which reflects an organization's ability to deploy its assets profitably, and return on equity (ROE), which measures the returns produced on the owners' investments (Lafourcade et al., 2005). ROE calculations should use starting equity, unless there has been a substantial infusion of new equity from an outside source during the reporting period. These are appropriate indicators for institutions that do not receive subsidies. But donors and social investors typically deal with institutions that receive substantial subsidies, most often in the form of grants or 
loans at below-market interest rates. In such cases, the critical question is whether the institution will be able to maintain itself and grow when subsidies are no longer available. To determine this, financial reporting must be 'adjusted' to reflect the impact of the present subsidies, such as subsidized cost of funds, in-kind subsidy and inflation. Operational self-sufficiency (OSS) is a subsidy-adjusted indicator often used by donor-funded NGOs. It measures the extent to which an MFI's operating revenue-mainly interest received-covers the adjusted costs (Note 3). If it is below $100 \%$, then the MFI has not yet achieved breakeven. It generally includes all the cash costs of running an MFI, depreciation and the loan loss reserve. Therefore, it has become one of the major goals for MFIs to achieve in order to maintain viability and further grow their operations.

In the context of the microfinance industry, this paper has investigated trade-off between financial and social performance of MFIs based on the interaction effects of capital structure and scale of operation on financial performance. Previous studies tend to use lending methods, share of lending to women, mature and savings in order to explain investigate the determinants of the performance of MFIs. This paper has introduced new evidence and possible explanations from an explicit perspective that might be relevant in the context of scale of operational, profit status, regulated status and legal status by using the dynamic system GMM of Blundell \& Bond (1998) in order to solve the endogeneity problem.

\section{Managing Trade-Offs between Financial and Social Performance}

Many studies have found that there is a strong link between sustainability and outreach (Ledgerwood \& White, 2006). Debates about the potential for microfinance to achieve social as well as financial goals are, however, hindered by a lack of information, in particular on social performance. This lack reinforces the tendency to focus on what is measurable and available in financial statements. As the win-win vision of microfinance is difficult to achieve in practice, there has been tendency over the past years to emphasize the financial, rather than the social, objectives of microfinance. The social objective seems to lead MFIs to over-lend in certain situations (i.e. to achieve massive outreach) by not providing microfinance to the right people. In a situation where donor support is linked to strictly applied timetables for the achievement of financial self-sufficiency, the very future of most MFIs depends on the realization of these goals. It is often feared that there are insufficient public funds for the subsidized microfinance programs, and that MFIs cannot remain viable. In addition, the poor tend to borrow from financially viable MFIs (Zeller \& Meyer, 2003), which seems to suggest a win-win situation, in which MFIs and the poor can earn profits. For these reasons, MFIs ideally focus on viability by reaching the economically active poor with small potential profit businesses, instead of focusing on the number of borrowers (Hammill et al., 2008). Clearly, sustainability is valued for what it brings to the clients of microfinance.

It is useful to think of microfinance performance as a pie. Initially, the size of the pie will depend on how well an MFI achieves its goals. The way the pie is sliced could affect its goals. If so, MFIs need to manage trade-offs that affect the size of the pie as large as it can be. MFIs can manage their social and financial performance, extend their frontiers and adjust the balance of social and financial objectives by adjusting products, services, organizational culture, staff incentives, and management systems. This requires information. For financial performance this is available, but measures of social performance are at an early stage of development. Given the lack of social performance data, MFIs often have to make operational decisions based on financial performance alone. Consequently, they are much more likely to respond to financial pressures and signals in their management information systems, and to make decisions that tend to prioritize financial over social objectives.

MFI managers need information for day-to-day and strategic decisions on social and financial performance. The possible decision-making tool combines social and financial information (Note 4) given on the nature and the relative magnitude (neutral, small, large) of any trade-off between financial performance and social impacts. Such information would allow managers to make more informed decisions in their daily performance management. It would also allow for decisions to be made where trade-offs exist between social and financial objectives; for example, allowing for donor investment in activities that yield high social and low financial returns.

\section{Theoretical Framework}

\subsection{Institutionist Approach}

The institutionist approach is characterized by the argument that successful poverty reduction requires massive scale of operation, given the number of poor households and the demand for microfinance. This massive scale in turn requires massive financial resources, which are far beyond the ability of traditional NGOs and aid donors to provide. Even if donors had sufficient resources, they would be subject to fads, trends have their own agendas, and would not be a reliable long-term source of funds. It is from this "recognition of scarcity" that springs the institutionists' concern for operational self-sufficiency. According to this approach, microfinance institutions tend to generate the highest return in order to attract investments funds and more investors to expand their 
business, service more poor households and therefore alleviate poverty (Schreiner, 2003; CGAP, 2003).

In addition, receiving subsidies in the form of aid is damaging to the microfinance industry (Hollis \& Sweetman, 1998). The success of an institution is measured by its progress towards operational self-sufficiency, while a positive impact on the client is assumed (Hulme \& Mosley, 1996; Otero, 1999; Rhyne, 2001; Copestake, 2007; Hammill et al., 2008). The only way to attract the requisite financial resources is by choosing the optimal financing mix between private and public capital. However, the widespread access to private capital requires that MFIs operate efficiently and profitably. To guide the industry's transition to for-profit status, institutionists have spent much time in an attempt to design a set of best practices which refers to those practices that improve institutional efficiency and effectiveness. It has become an essential step on the path to industry-wide operational self-sufficiency, capital market access and maximum outreach to poor clients.

\subsection{Welfarist Approach}

In contrast to the institutionists, the welfarists argue that attaining financial sustainability is not a pre-requisite for becoming a sustainable MFI (Woller et al., 1999). They distinguish themselves from institutionists primarily by their value-based commitment to serve the very poor by placing greater weight on depth of outreach than on breadth (Hossain and Knight, 2008). According to this approach, grants, funds and subsidies are types of equity which are donated by social investors, who are distinguished from private investors by their willingness to sacrifice financial returns (or accept minimal ones) by investing in an institution that has a social mission focus. MFIs which can secure a regular stream of subsidies, including untied aid, can also be deemed institutionally viable (Woller et al., 1999). Therefore, they emphasize the measurement of variables that determine the level of social impact. This does not mean that the variables for the measurement of financial sustainability are useless, but welfarists believe that the social mission needs to be given greater consideration. There are a number of reasons why institutionists have posed a perceived threat to welfarists. Commercial microfinance need to satisfy the 'selfish' demands of outside investors and means that the social mission is replaced by the profit motive (Dichter \& Harper, 2007). The call for donors to withdraw support from unsuccessful programs will result in a resource allocation on the basis of financial performance, regardless of actual program impact. This may push the poor, particularly the poorest, out of microfinance.

\section{Literature Review}

Microfinance has proven to be an appropriate, effective and powerful tool for poverty reduction (Cohen, 2003; Lafourcade et al., 2005; Dichter \& Harper, 2007; Hossain \& Knight, 2008; Rosenberg, 2009; Littlefield \& Kneiding, 2009; Hermes et al., 2011). The debate between institutionists and welfarists is likely to continue, not least because of a lack of definitive evidence about the actual capacity of microfinance to alleviate poverty (Zeller \& Meyer, 2002; Cull et al., 2007, 2011). However, the influence of the institutionist approach is clearly evident, in that its terms and concepts (e.g., sustainability, outreach and profitability) have become the lingua franca of the microfinance industry. Most research on microfinance performance during the late 1990s, adopted the institutionist approach to analysing the sustainability situation of MFIs (Rhyne, 1998).

Researchers around the world have started measuring the actual long-term social impact of microfinance. In fact, it has been extensively examined over the past 20 years, and the resulting studies show that microfinance does have positive and significant effects on the poor in certain situations (Bartle, 2008; Roodman, 2009). In spite of the fact that some studies were conducted using different approaches and point to different conclusions, they are all ready to accept that it is extremely difficult to separate and measure the contributions of microfinance to poverty reduction, since poverty is a significant social problem that permeates every dimension of culture and society (De Aghion \& Morduch, 2005; Dichter \& Harper, 2007; Odell, 2010; Orso, 2011). Poverty reduction, therefore, is ideally a long-term process, integrating numerous financial and non-financial programs for generations of poor households (Morduch \& Haley, 2002; Aigbokhan, 2008). The results suggest that microfinance cannot immediately turn the poor into non-poor. The point is that microfinance is a long-term process which tends to support the poor financially so that they can combine their skills, knowledge, experience and financial capital in order to break away from poverty and change their lives for a better and brighter future. Moreover, the results also show that MFIs need to move out of heavily subsidized operations and into commercialization to achieve efficiency and sustainability (Ledgerwood \& White, 2006). When donor funding becomes insufficient to meet the continual demand for well-designed financial products from new and existing clients, access to commercial funds tends to help MFIs improve their performance. This clearly suggests that they may reach sustainability (financial performance) to achieve a targeted outreach (social performance). In addition, funding microfinance plays an important role in MFIs being economically viable and sustainable, as well as being able to provide financial services to the poor in the long run. 
According to Woller et al. (1999), the institutionist approach, which emphasizes on operational self-sufficiency and scale of operation, appears to have gained ascendancy over the welfarist one, with its emphasis on the very poor. Therefore, microfinance is tending to deviate from its social objective towards a focus on generating profits and may not reach the poorest of the poor. Increasing interest rates and average loan sizes in order to secure a client base are considered as the signs of the trade-off between financial sustainability and social mission (Lafourcade et al., 2005; Ledgerwood \& White, 2006; Hermes \& Lensink, 2007). MFIs need to operate in order to achieve two bottom lines: alleviating poverty for clients and generating profits for investors (Zeller \& Meyer, 2002; Charitonenko \& Rahman, 2002; Hammill et al., 2008).

With regard to the trade-offs in microfinance, there have in particular been some discussions about the poorest or the poor just above the poverty line, who really benefit from microfinance. Since donor funding is becoming insufficient to meet the continual demand for well-designed financial products from new and existing clients, MFIs are tending to access commercial funds to improve their performance and also achieve a targeted outreach (Ledgerwood \& White, 2006). Therefore, there has been some discussion about the incentives to serve the poorest of the poor. Several MFIs focus on serving the poor who are near or just above the poverty line, instead of the very poorest. It is sometimes argued that microfinance has contributed positively to the well-being of the poor in general, but it has failed to reach the poorest in particular.

Cull et al. $(2007,2011)$ provide a new dimension to the financial performance of MFIs, based on an extensive comparison of 124 from 49 countries. The study gives some empirical evidence for a trade-off between the depth of outreach and profitability by examining whether more profitability is associated with a lower depth of outreach, and whether there is a move from serving the absolutely poor to wealthier ones in order to achieve higher sustainability (mission drift). It also examines whether an increase in lending interest rates affects the loan portfolio due to adverse selection and moral hazard. The advocates of the social approach would argue that the poorest cannot afford higher interest rates; therefore, financial sustainability in microfinance goes against the aim of serving large groups. The results are consistent with the finding of Rosenberg (1996), Fernando (2006), Hermes and Lensink (2007), Hermes et al. (2011), Zerai and Rani (2012), Ngo et al. (2014) and Nurmakhanova et al. (2015) in different regions.

There is disagreement on the benefits of the depth and breadth of outreach. The non-profit MFIs would rather reach out to the poorest; therefore, depth of outreach is more important for achieving their social objective, whereas the proponents of sustainable microfinance are more interested in opening access to a wide range of unserved or underserved clients (Rhyne, 1998). 'Breadth matters since the poor are many but the aid dollars are few' (Navajas et al., 2000, p. 336). Based on the breadth logic, MFIs should have large-scale outreach in order to make a difference to the world's poverty levels. Some argue that shallow depth can be compensated for by breadth of outreach or that it is even more important than depth (Navajas et al., 2000; Robinson, 2001). The objective functions might thus differ in the weight MFIs assign to different aspects of outreach. The common approach has been to study outreach by investigating the impact of microfinance and how to achieve this outreach.

In summary, the literature shows that neither sustainability nor social mission (outreach) is better or more important for MFIs. Rather, it is necessary to have the right mixture because they are typically similar to each other. Ultimately, this combination assures that an MFI can make profits which are reinvested into the business, so it may operate longer. The crucial intention of microfinance is not to have a return on equity but to help the poor alleviate poverty by making them bankable. Nevertheless, an MFI has to take many aspects into account and decide, even before setting up a business, which goals should be achieved. This suggests that good governance is the first step towards a sustainable enterprise, which can only become sustainable with profitable elements. Since many MFIs do not collect basic social performance data, such as the poverty level of their clients, they are often unaware of the impact of these incentives and cannot correct the 'mission drift'. Through analysis and programme design, greater depth of outreach can be achieved. This can, but must not always, affect financial performance. Therefore, this paper outlines some of the parameters that affect the nature of trade-offs between social and financial objectives in microfinance, and provides empirical evidence from cross-country analysis.

\section{Models}

The literature suggests that MFIs may take on more debts to achieve a positive impact on sustainability and to have the ability to expand their outreach. This increases the need to carry out an empirical investigation to shed new light on the existence of the trade-offs between financial sustainability and social outreach of MFIs. It is hypothesized that sustainability can promote the outreach of MFIs. In this paper, we focus on performing the 
following regression analysis devised by Ngo et al. (2014):

$$
\text { OSS }_{i t c}=\alpha+\beta_{1} \text { OSS }_{i t c-1}+\beta_{2} \text { Outreach }_{i t c}+\sum_{i=1}^{4} \beta_{3}^{i} F S V_{i t c}+\sum_{i=1}^{3} \beta_{4}^{3} M E V_{t c}+\varepsilon_{i t c}
$$

where OSS (operational self-sufficiency) refers to sustainability; outreach is measured by using average loan balance (ALB, log) and number of active borrowers (NAB, log) as the depth and the breadth of outreach. FSV $\mathrm{V}_{\text {itc }}$ represents other firm-specific variables, including financial leverage (DTE) and dummy variables $\left(D_{P}, D_{L}\right.$ and $\left.D_{R}\right)$ referring to profit status (profit or nonprofit), legal status (bank, credit union, NGO or non-bank financial institution - NBFI) and regulated status (regulated or unregulated). $\mathrm{MEV}_{\mathrm{tc}}$ represents macroeconomics variables, including inflation, GNI per capita and a dummy variable referring to the global financial crisis of 2007/2008 (before and after the crisis); $\alpha$ is constant; $\beta$ is a variable coefficient and $\varepsilon_{i t c}=\vartheta_{i}+\gamma_{t}+\mu_{i t c}$ is an error term that includes $\vartheta_{i}$ (the unobserved complete set of the MFI-specific effect), $\gamma_{t}$ (the unobserved time effect) and $\mu_{i t c}$ (the idiosyncratic error).

This paper contributes to the literature by applying a dynamic model with system GMM estimation to a dataset covering all MFIs around the world for the period from 1995-2013. The microfinance data was collected from MIX Market, which has an extensive historical dataset, tracking industry development since the 1990s. All data entered into the database is reviewed by MIX staff and validated against a set of business rules before publication (including more than 135 quality checks and over 150 audit rules) (MIX Market, 2015). All data submitted to MIX in most cases is unaudited, but MIX cleans its data extensively in order to help analysts follow-up with MFIs when necessary. Therefore, the missing data means the institution did not submit that data to MIX or it is no longer in operation. The macroeconomic data was collected from Thomson Reuters Datastream. In addition, we also test for the nonlinear relationship between financial sustainability and social outreach (i.e. the threshold in the trade-offs), as well as including the impact of the global financial crisis, and therefore controlling for global vulnerability and any structure break in the data sample. Two different specifications are the squared term of all variables and the interaction term of financial leverage and MFI-specific characteristics. However, there are several reasons for the extraordinary results. First, it is referred to the number of MFIs registered and reported to the central banks with regard to their financial statements. Second, several microfinance programs have been operating as a part of the 'non-microfinance' projects carried out by NGOs and international organisations for a specified period of time (such as the community resilience to natural disasters project was sponsored by CARE International). Third, local governments have acted as regulators and main active microfinance providers via state-owned banks. Four, microfinance has begun to develop as an industry in the 1990s. This result is entirely consistent with the findings of MicroRate (2013). It is likely that the lack of data is impossible to establish a good data set. Any conclusions from the proceeding analysis will therefore be somewhat limited. This has been the nature of MFI analysis: limited data followed by limited conclusions.

Table 1 shows that the value of DTE was 4.4125 times on average. There is a big gap between the minimum value $(-1,221.26$ times) and the maximum value $(2,940.2$ times). DTE gives a measure of how much of the company's worth is funded through debt and how much through equity. A ratio of greater than 1 means that the MFI has less equity than total liabilities; a ratio of greater than 0 but less than 1 means that it has more equity than total liabilities. These rules apply only so long as the MFI has positive equity. A negative DTE would indicate that many MFIs have negative equity, when total liabilities exceed total assets. This suggests that MFIs depend heavily on borrowings and subsidized funds for lending, which leads to MFIs having negative equity since they do not earn enough revenue to cover total costs. This indicator provides the level of dependence on external funds for their expansion.

Table 1. Descriptive statistics of all variables

\begin{tabular}{lccccc}
\hline \multicolumn{1}{c}{ Variable } & Mean & Max & Min & Std. Dev & Obs. \\
\hline OSS & 1.1847 & 19.38 & -0.29 & 0.6871 & 4,570 \\
ALB & $1,166.77$ & $99,889.5$ & 0 & $2,799.52$ & 4,657 \\
NAB & $59,619.96$ & $6,397,635$ & 0 & $338,013.5$ & 4,684 \\
DTE & 4.4125 & 2940.2 & $\mathbf{- 2 , 4 7 8 . 2 4}$ & 82.7328 & 4,671 \\
CPB & 292.85 & 179,116 & 0 & $3,813.71$ & 3,653 \\
Inflation & 8.1367 & 431.7 & -13.23 & 16.7145 & 1,462 \\
GNI & 547.8553 & 999.99 & 80 & 244.976 & 1,692 \\
\hline
\end{tabular}


Table 2. Correlation matrix between the dependent and independent variables

\begin{tabular}{cccccccc}
\hline & OSS & ROA & ROE & DTE & InGLP & Inflation & InGNI \\
\hline OSS & 1.0000 & & & & & & \\
ROA & -0.0293 & 1.0000 & & & & & \\
ROE & -0.0308 & $0.0836^{*}$ & 1.0000 & & & & \\
DTE & -0.0112 & -0.0026 & -0.0168 & 1.0000 & & & \\
InGLP & $0.0431^{*}$ & 0.0237 & 0.0194 & -0.0004 & 1.0000 & & \\
Inflation & -0.0180 & -0.0296 & -0.0090 & -0.0241 & -0.0747 & 1.0000 & $-0.1356^{*}$ \\
InGNI & 0.0112 & $0.1156^{*}$ & 0.0426 & 0.0096 & $0.1830^{*}$ & & \\
\hline
\end{tabular}

Note. $*$ is statistically significant at a level of $5 \%$ or lower.

Table 2 shows that the Pearson correlation coefficients between all pairs of the independent variables are quite small. This indicates that there is a complete lack of multicollinearity in the model. In addition, the results of the White's test and the Breusch-Godfrey Lagrangian Multiplier test show that the variance of the error term is constant (homoscedasticity) and there is no serial correlation.

The GMM is the preferred method over OLS, GLS and TSLS since it helps to solve several econometric problems that may arise from estimating the equation above. First, the panel dataset with particular regard to this study (a cross-country analysis) has a short time dimension (T) and a larger country dimension $(\mathrm{N})$. The Arellano-Bond estimator was designed for small-T panels in order to remove any autocorrelation between the explanatory variables. Second, there is a possibility of reverse causation which makes variables correlate with the error term in the equation. Therefore, some explanatory variables are assumed to be endogenous. To cope with that problem (fixed effects), the GMM uses first-differences to transform the regressors in order to remove the fixed country-specific effect since it does not vary with time. Third, the presence of the lagged dependent variable gives rise to autocorrelation. Therefore, the lagged levels of the endogenous regressors (i.e. the first-differenced lagged dependent variable) is added to the explanatory variables and also instrumented with its past levels. This makes the endogenous regressors pre-determined and, therefore, not correlated with the error term. In addition, the GMM is also preferred to fixed effect model (FEM), as well as random effects model (REM) since in small-T panels a shock to the country's fixed effect, which shows in the error term, will not decline over time. In addition, the correlation of the lagged dependent variable with the error term will be significant. Therefore, the fixed effect model does not allow for controlling of the unobserved heterogeneity which describes individual specific effects that are not captured by observed variables (this means that there is no evidence of individual effects in the data). Since REM is considered as a special case of FEM and also does not allow one to capture the unobserved effects by the error term, consisting of an individual specific one and an overall component which is the combined time series and cross-section error.

To avoid an unbalanced two-way error component model, we add the country-specific dummy into the regression model and test country and time hypotheses separately as well as jointly by the Lagrange Multiplier (LM) test. The results show that country and time specific dummy variables are insignificant for a cross-country analysis. Therefore we should neither include year-specific nor country-specific dummies in the model. In addition, we perform the Sargan test for over-identifying restrictions in the GMM dynamic model estimation to confirm the validity of the instruments, as well as also testing whether the Arellano-Bond orthogonality conditions are fulfilled. In all regressions, the lags of dependent variables are statistically significant in order to justify our use of the system GMM.

\section{Trade-Off between Sustainability and Outreach}

Table 3 shows that loan size (ALB-average loan balance) and number of active borrowers (NAB) were positively related to sustainability and were significant $(0.0530$ and 0.0510$)$ at a level of $1 \%$. This may point to the fact that MFIs can expand their outreach to achieve sustainability based on the advantages of economies of scale. MFIs need to convert from credit-only NGOs into regulated MFIs in order to provide other financial services to their clients. Consistent with the previous findings, this conversion allows MFIs take on more debts, especially savings, as well as to offer a greater basket of products and services (Cull et al., 2007, 2011; Hermes et al., 2011; Zerai \& Rani, 2012; Ngo et al., 2014; Nurmakhanova et al., 2015). Due to the causal relationship between sustainability and outreach, sustainable MFIs tend to serve the large majority of borrowers, since on average they are much larger than unsustainable ones. This suggests that we should weigh the results by number of borrowers or gross loan portfolio. It would make no sense to give each of the hundreds of tiny MFIs the same weight as one large one. Furthermore, most of the investors who identify themselves as socially responsible will 
not apply a negative screen or accept a lower return and higher risks than any other commercial investors. Clearly, government MFIs tend to be unsustainable and will continue to be so. However, the proposition that microfinance can be a perfectly viable business in most settings has been demonstrated very compellingly by now.

Table 3. Trade-off between sustainability and outreach

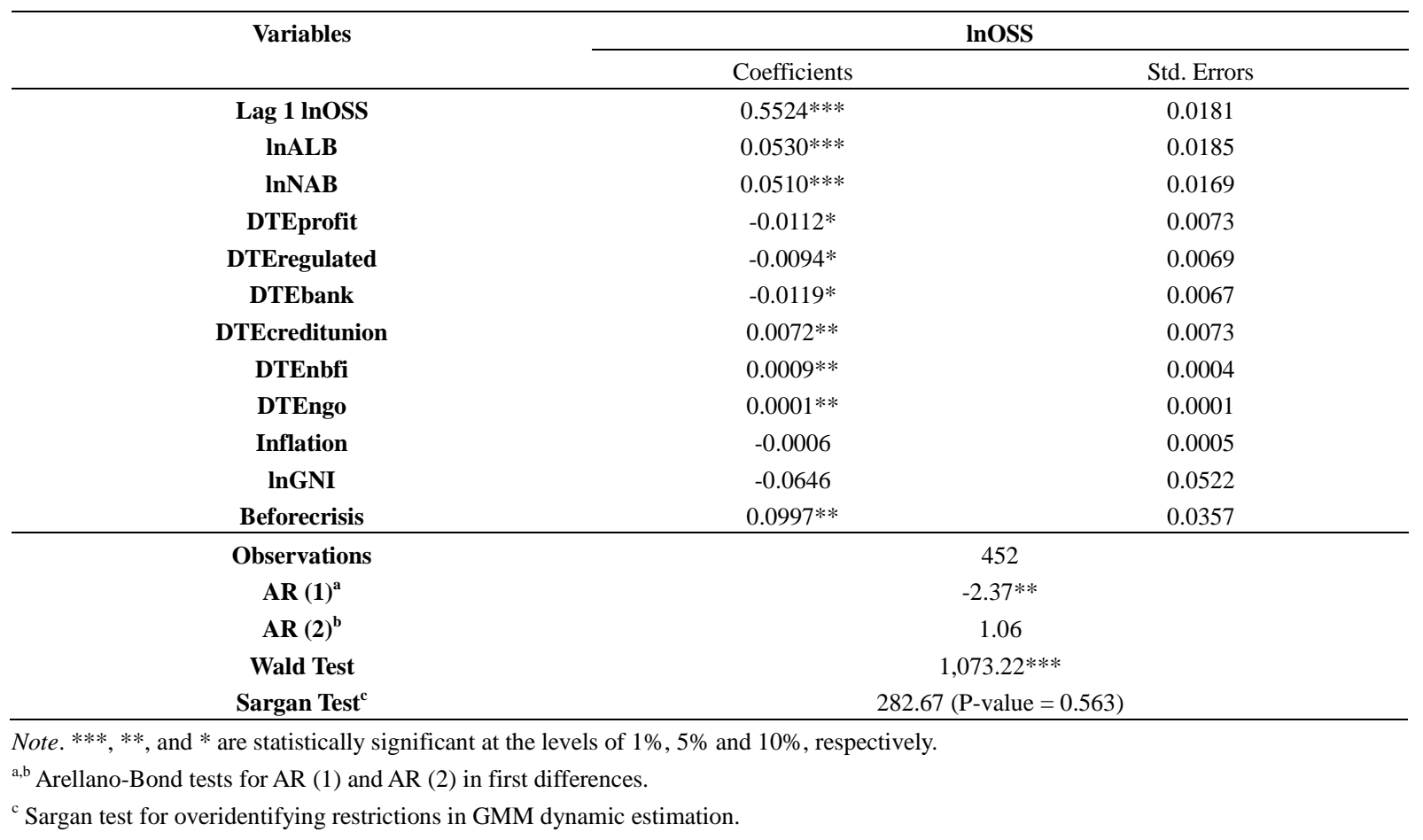

There is significant statistical difference in the relationship between capital structure and sustainability due to the differences in legal status which contribute to the impact of capital structure on performance in various ways. However, the results follow the theoretical predictions. A negative and significant relationship at the 0.1 level was found between capital structure and sustainability in the profitable and regulated MFIs (see Table 3 above). Interestingly, regulated MFIs have been found to be less efficient and to face many disadvantages from being regulated, such as cost increases from licensing fees, savings mobilization, capital requirements, control of interest rates and networks. The cost of compliance, as well as the cost of savings mobilization and regulation, is very high. This leads to an increase in expenses and results in revenue which is lower than costs. Therefore, MFIs need to achieve a significant scale of operation and degree of sustainability before becoming regulated and profitable. Large MFIs are cost efficient, since they tend to pay more attention to the purposes of loans and to provide sufficient loan sizes to the appropriate borrowers on a commercial basis (Ngo et al., 2014).

On the contrary, a weak positive and significant relationship at the 0.05 level was found between capital structure and sustainability in credit unions, NBFIs and NGOs. These results suggest that taking on considerably more subsidies and commercial funds with a low cost of capital are expected to lead to have more revenue than costs and to higher sustainability. This finding should encourage the transformation process of MFIs, from simply achieving their social mission to becoming profitable and regulated in order to provide savings when subsidies dry up and to become self-sufficient. Taken together, the mixed results among MFIs with different legal statuses point to the interactions of financial leverage, scale of operation and MFI-specific characteristics, as well as the nonlinear relationship between capital structure and sustainability.

The relationships between sustainability, inflation and GNI per capita were weak and negative but statistically insignificant. Poverty is a significant social problem that permeates every dimension of culture and society. Therefore, it is extremely difficult to separate and measure the contributions of microfinance to poverty reduction. In addition, there are strong potential synergies between microfinance and the provision of other non-financial programs since the benefits derived from these programs are interconnected (Morduch \& Haley, 2002). The global financial crisis and a high inflation rate commonly create obstacles for MFIs and poor 
borrowers by increasing the cost of living, cost of capital and other expenses. Therefore, MFIs tend to consider reducing costs for borrowers and to help them solve their financial problems and repay their loans. However, poor borrowers prefer to deal with local commercial banks after becoming wealthier and being lifted out of poverty since they may require the larger loans provided by these banks to meet their financial demands. Large MFIs have no choice but to build precautionary savings by serving wealthier clients who may have been less affected by the financial crisis. The poorest of the poor are commonly the ones who will be most affected, irrespective of the continent, country, urban or rural area where they live.

Table 4 shows that the coefficient for the first term (lnALB, $\operatorname{lnNAB}$ and DTE) is significantly positive (or negative) and the coefficient for the squared term $\left(\ln \mathrm{ALB}^{2}, \operatorname{lnNAB}{ }^{2}\right.$ and $\mathrm{DTE}^{2}$ ) is significantly negative (or positive). This tells us that there is a threshold that makes the relationship between variables reverse if it goes beyond that point. Clearly, the results also provide strong evidence that there is an optimal mix of sustainability and outreach. Furthermore, they tend to vary with the heterogeneity of MFI characteristics. This also provides us with evidence of a trade-off between sustainability and outreach beyond the threshold. It also suggests that MFI managers need to focus on increasing the level of thresholds to achieve a higher level of sustainability and a wider outreach.

Table 4. Trade-off between sustainability and outreach

\begin{tabular}{|c|c|c|}
\hline Variables & Coefficients & Significant levels \\
\hline $\ln A L B$ & $-1.4748 * * *$ & $1 \%$ \\
\hline $\ln A L B^{2}$ & $0.1174 * * *$ & $1 \%$ \\
\hline $\operatorname{lnNAB}$ & $0.0069^{* *}$ & $5 \%$ \\
\hline $\operatorname{lnNAB}{ }^{2}$ & $-0.0069^{* *}$ & $5 \%$ \\
\hline DTE & $0.0817^{*}$ & $10 \%$ \\
\hline DTE $^{2}$ & $-0.0561^{* *}$ & $5 \%$ \\
\hline DTEprofit & 0.0067 & na \\
\hline DTE $^{2}$ profit & -0.0008 & na \\
\hline DTEregulated & -0.0126 & na \\
\hline DTE² regulated & 0.0005 & na \\
\hline DTEbank & -0.0474 & na \\
\hline DTE $^{2}$ bank & 0.0016 & na \\
\hline DTEcreditunion & 0.0094 & na \\
\hline DTE $^{2}$ creditunion & -0.0041 & na \\
\hline DTEnbfi & 0.0159 & na \\
\hline DTE $^{2}$ nbfi & -0.0004 & na \\
\hline DTEngo & 0.0069 & na \\
\hline DTE $^{2}$ ngo & $-5.49 \mathrm{e}-06$ & na \\
\hline Inflation & -0.0063 & na \\
\hline Inflation $^{2}$ & 0.0001 & na \\
\hline InGNI & -1.1185 & na \\
\hline $\operatorname{lnGNI}^{2}$ & 0.0675 & na \\
\hline Beforecrisis & 0.0951 & na \\
\hline
\end{tabular}

One of the best ways to shift the threshold is by raising effective interest rates to meet the demands of higher profitability, by which MFIs would have the ability to earn sufficient income to cover the full costs of operation. In addition, they may also need to create an environment to attract the poor by providing vocational training, counselling, mentoring and market analysis through partnerships with training institutions. This will provide a platform for the poor to enter self-employment in groups through close collaboration with MFIs. In the long run, MFIs will be able to ensure an increase in their clientele, closely monitor them, ensure sustainability and ultimately achieve their social missions.

\section{Conclusions}

The notion of best practices may well mask the complexity of microfinance and its trade-offs. Standardized assessments do not always fully take account of the operating environment or the social benefits that may result from investment in an MFI with strong social objectives. The contributions of this paper are threefold. First, there is strong evidence that there exists the trade-off between outreach and sustainability. The results suggest 
that MFIs need to upscale their operations and transform themselves into regulated MFIs in order to achieve a higher level of sustainability and to expand their outreach. Second, an interesting issue has emerged which is that successful MFIs tend to shift their mission and practices with the changes in their clients, who will become less poor and need larger loans over time. This means that MFIs are able to reach larger numbers of the poor and have the ability to offer bigger loans to meet the increasing demands of the poor after expansion of their scale of operation. The results also highlight a trade-off between existing wealthier and poorer clients among existing clients, as well as a one between depth and breadth of outreach. Third, the relationship between outreach and sustainability is nonlinear, implying that beyond a certain threshold MFIs perform well, at the expense of outreach.

\section{References}

Aigbokhan, B. E. (2008). Growth, Inequality, and Poverty in Nigeria. Economic Commission for Africa, ACGS/MPAMS Discussion Paper, No.3, February. United Nations Economic Commission for Africa (UNECA).

Bartle, P. (2008). Factors of Poverty: The Big Five. Workshop Notes, Community Empowerment Collective. Retrieved from http://cec.vcn.bc.ca/cmp/modules/emp-pov.htm

Blundell, R., \& Bond, S. (1998). Initial conditions and moment restrictions in dynamic panel data models. Journal of Econometrics, 87(1998), 115-143. http://dx.doi.org/10.1016/S0304-4076(98)00009-8

CGAP. (2003). Microfinance means services for the poor. Consultative Group to Assist the Poor (CGAP) Donor Brief, No.11 March, Washington, D.C: CGAP.

Charitonenko, S., \& Rahman, S. (2002). Commercialization of Microfinance: Bangladesh. Manila (Philippines): Asian Development Bank (ADB).

Cohen, M. (2003). The Impact of Microfinance. CGAP Donor Brief 13. Consultative Group to Assist the Poor (CGAP). Retrieved from http://www.cgap.org/gm/document-1-9.2407/DonorBrief_13.pdf

Copestake, J. (2007). Mainstreaming Microfinance: Social Performance Management or Mission Drift? World Development, 35(10), 1721-1738. http://dx.doi.org/10.1016/j.worlddev.2007.06.004

Copestake, J., Greeley, M., Johnson, S., Kabeer, N., \& Simanowitz, A. (2005). Money with a Mission. Microfinance and Poverty Reduction. Warwick, UK: ITDG Publishing. http://dx.doi.org/10.3362/9781780440866

Cull, R., Demirguc-Kunt, A., \& Morduch, J. (2007). Financial Performance and Outreach: A Global Analysis of Leading Microbanks. The Economic Journal, 117(517), 107-133. http://dx.doi.org/10.1111/j.1468-0297.2007.02017.x

Cull, R., Demirguc-Kunt, A., \& Morduch, J. (2011). Does Regulatory Supervision Curtail Microfinance $\begin{array}{llll}\text { Profitability and } \quad \text { Outreach? } & \text { Wevelopment, 39(6), }\end{array}$ http://dx.doi.org/10.1016/j.worlddev.2009.10.016

De Aghion, A. B., \& Morduch, J. (2005). The Economics of Microfinance. Cambridge: The MIT Press.

Ditcher, T., \& Harper, M. (2007). What's Wrong with Microfinance? Rugby, United Kingdom: Practical Action.

Fernando, N. A. (2006). Understanding and Dealing with High Interest Rate on Microcredit. A Note to Policy Makers in the Asia and Pacific Region. Manila (Philippines): Asian Development Bank (ADB).

Gonzalez, A. (2010). Is Microfinance Growing Too Past? MIX Data Brief No. 5. Retrieved from http://ssrn.com/abstract=1644948

Hammill, A., Mathew, R., \& McCarter, E. (2008). Microfinance and Climate Change Adaptation. Institute of $\begin{array}{lllll}\text { Development } \quad \text { Studies. } & \text { IDS }\end{array}$ http://doi.wiley.com/10.1111/j.1759-5436.2008.tb00484.x

Hermes, N., Lensink, R., \& Meesters, A. (2011). Outreach and Efficiency of Microfinance Institutions. World Development, 39(6), 938-948. http://dx.doi.org/10.1016/j.worlddev.2009.10.018

Hollis, A., \& Sweetman, A. (1998). Microcredit: What Can We Learn from the Past? World Development, 26(10), 1875-1891. http://dx.doi.org/10.1016/S0305-750X(98)00082-5

Hossain, F., \& Knight, T. (2008). Can microcredit improve the livelihoods of the poor and disadvantaged? Empirical observations from Bangladesh. International Development Planning Review, 30(2), 155-175. http://dx.doi.org/10.3828/idpr.30.2.4 
Hulme, D., \& Mosley, P. (1996). Finance against Poverty (Vol. 1). London: Routledge.

Lafourcade, A. C., Isern, J., Mwangi, P., \& Brown, M. (2005). Overview of the outreach and financial performance of microfinance institutions in Africa. MicroBanking Bulletin April 2006, Future Articles. Retrieved from http://www.themix.org/sites/default/files/MBB\%2012\%20-\%20Outreach\%20and\% 20Financial\%20Performance\%20of\%20African\%20MFIs.pdf

Ledgerwood, J., \& White, V. (2006). Transforming Microfinance Institutions: Providing full financial service to the poor. Washington, D.C.: World Bank, Microfinance Network and SIDA. http://dx.doi.org/10.1596/978-0-8213-6615-8

Littlefield, E., \& Kneiding, C. (2009). The Global Financial Crisis and Its Impact on Microfinance. CGAP Focus Note, No. 52, Washington, D.C.

MicroRate. (2013). Microfinance Institution Tier Definitions. MicroRate. Retrieved from http://www.microrate.com/media/downloads/2013/04/MicroRate-White-paper-Microfinance-Institution-Tie r-Definitions.pdf

MIX Market. (2015). About MIX. Microfinance Information Exchange. Retrieved from http://www.mixmarket.org/about

Morduch, J., \& Haley, B. (2002). Analysis of Effects of Microfinance on Poverty Reduction. NYU Wagner Working Paper, 28(1014), 84-97.

Navajas, S. M., Schreiner, R., Gonzalez-Vega, C., \& Rodriguez-Meza, J. (2000). Microcredit and the poorest of the poor: Theory and Evidence from Bolivia. World Development, 28(2), 333-346. http://dx.doi.org/10.1016/S0305-750X(99)00121-7

Ngo, T., Mullineux, A., \& Ly, A. (2014). The impact of scale of operation on financial performance in microfinance. Eurasian Economic Review, 4(2), 177-198. http://dx.doi.org/10.1007/s40822-014-0011-4

Nurmakhanova, M., Kretzschmar, G., \& Fedhila, H. (2015). Trade-off between financial sustainability and outreach of microfinance institutions. Eurasian Economic Review, 5(2). http://dx.doi.org/10.1007/s40822-015-0016-7

Odell, K. (2010). Measuring the Impact of Microfinance: Taking Another Look. Washington, DC: The Grameen Foundation.

Orso, C. E. (2011). Microcredit and poverty: An overview of the principal statistical methods used to measure the program net impacts. POLIS Working Papers, 180, 1-47.

Otero, M. (1999). Bringing Development Back, Into Microfinance. Journal of Microfinance, 1(1), 8-19.

Rhyne, E. (1998). The Yin and Yang of microfinance: Reaching the poor and sustainability. The MicroBanking Bulletin, 2, 6-9.

Rhyne, E. (2001). Mainstreaming Microfinance: How Lending to the Poor Began, Grew and Came of Age in Bolivia. West Hartford: Kumarian Press.

Robinson, M. S. (2001). The Microfinance Revolution: Sustainable Finance for the Poor. Washington, D.C.: World Bank. http://dx.doi.org/10.1596/0-8213-4524-9

Roodman, D. (2009). What Do We Really Know About Microfinance's Impact? CGAP Microfinance Gateway, The Consultative Group to Assist the Poor (CGAP). Retrieved from http://www.microfinancegateway.org/p/site/m/template.rc/1.26.11408

Rosenberg, R. (1996). Microcredit Interest Rates. The Consultative Group to Assist the Poor (CGAP), Occasional Paper No. 1, Washington, D.C.: CGAP.

Rosenberg, R. (2009). Measuring Results of Microfinance Institutions. Minimum Indicators That Donors and Investors Should Track. CGAP A Technical Guide. Consultative Group to Assist the Poor, Washington, D.C.

Schreiner, M. (2003). A Cost Effectiveness-Analysis of the Grameen Bank of Bangladesh. Development Policy Review, 21(3), 357-382. http://dx.doi.org/10.1111/1467-7679.00215

Woller, G. M., Dunford, C., \& Woodworth, W. (1999). Where to microfinance. International Journal of Economic Development, 1(1), 29-64.

Worakul, W. (2006). Thailand's Best Practices and Lessons Learned Community-based Microfinance: An 
Empowering Approach Towards Poverty Alleviation and Community Self-Reliance. UNDP Thailand and Ministry of Foreign Affairs of Thailand.

Zerai, B., \& Rani, L. (2012). Is There a Trade-off between Outreach and Sustainability of Microfinance Institutions? Evidence from Indian Microfinance Institutions (MFIs). European Journal of Business and Management, 4(2), 90-98.

Zeller, M., \& Meyer, R. (2003). The Triangle of Microfinance: Financial Sustainability, Outreach and Impact. Washington, D.C.: The International Food Policy and Research Institute.

\section{Notes}

Note 1 . The term 'moderately poor' refers to poor people who are near the poverty line and have a daily income of between US\$1.25 and US\$ 2.0 (Cohen, 2003; Hammill et al., 2008).

Note 2. Sustainability and profitability are used interchangeably, but they signify different terms. Sustainability refers to the ability of a firm to cover all expenses from operating income in order to be economically viable. On the other hand, profitability refers to the condition of yielding a financial profit or gain.

Note 3. Operating expenses include financial expenses, loan loss provision and operating expenses.

Note 4. Indicators include (i) gross loan portfolio outstanding, average loan size, staff productivity, savings (financial information); (ii) reaching target market, client loyalty, client satisfaction (social information); (iii) individual and household, and wider community.

\section{Copyrights}

Copyright for this article is retained by the author(s), with first publication rights granted to the journal.

This is an open-access article distributed under the terms and conditions of the Creative Commons Attribution license (http://creativecommons.org/licenses/by/3.0/). 